\title{
The non-transitivity of the contingent and occasional identity relations
}

\author{
(forthcoming in Philosophical Studies)
}

\author{
Ralf M. Bader
}

\begin{abstract}
АвSTRACT: This paper establishes that the occasional identity relation and the contingent identity relation are both non-transitive and as such are not properly classified as identity relations. This will be achieved by appealing to cases where multiple fissions and fusions occur simultaneously. These cases show that the contingent and occasional identity relations do not even satisfy the time-indexed and world-indexed versions of the transitivity requirement and hence are non-transitive relations.
\end{abstract}

\section{Introduction}

According to the standard understanding of the identity relation, identity is a nontemporary and non-contingent relation. It holds permanently and necessarily. If $\mathrm{x}$ and $\mathrm{y}$ are identical at one time, then they are identical at all times at which they exist. If $\mathrm{x}$ and $\mathrm{y}$ are identical in one world, then they are identical in all worlds in which they exist. This has been challenged by the occasional identity thesis and the contingent identity thesis. According to these alternative conceptions, identity can be restricted to particular worlds or times. ${ }^{I}$ In this paper, I will show that both the occasional identity relation and the contingent identity relation are non-transitive and thus do not classify as identity relations. This will be achieved by appealing to cases in which multiple fissions and fusions occur simultaneously. My discussion will focus on the account of occasional and contingent identity developed by André Gallois, but is equally applicable to other accounts.

\footnotetext{
${ }^{\text {IT }}$ The challenges are related in that a defender of occasional identity must also defend contingent identity, though not vice versa.
} 


\section{Occasional identity}

According to the Occasional Identity Thesis (OIT), two things can be identical at one time but distinct at another time.

$(\mathrm{OIT}) \diamond(\exists \mathrm{x})(\exists \mathrm{y})(\exists \mathrm{t})\left(\exists \mathrm{t}^{\prime}\right)\left[\right.$ at t: $\mathrm{x}=\mathrm{y} \&$ at $\left.\mathrm{t}^{\prime}: \neg(\mathrm{x}=\mathrm{y})\right]$

Gallois appeals to the occasional identity thesis in order to solve puzzle cases that involve objects that seem to be identical at one time but distinct at another time. In particular, OIT is relevant to cases of branching identity, such as the familiar cases involving amoebic division and brain transplantation. When fissions and fussions occur it seems that one object splits into two objects or that two objects fuse to become one object. According to Gallois, these puzzle cases are best described as cases of occasional identities.

While OIT does provide a nice account of various metaphysical puzzle cases, it faces a serious problem insofar as claiming that there really was only one object at $t$ and that this object is somehow identical to two objects at $\mathrm{t}^{\prime}$ is problematic since the transitivity of the identity relation seems to imply that there cannot be two objects at t' but only one.

Gallois attempts to get around this problem by restricting the transitivity requirement to objects existing at the same time and in the same world. This strategy, however, is not sufficient since we can establish the intra-temporal failure of transitivity when appealing to cases in which multiple fissions and fusions occur simultaneously.

Case I: At t, B splits into A and C. According to OIT, we get an occasional identity whenever we have an ordinary case of fission. In the present case the occasional identity is at $\mathrm{t}: \mathrm{A}=\mathrm{C}$.

For instance, consider a situation in which preservation of one brain half is sufficient for trans-temporal identity, i.e. if one brain half of $B$ is transplanted into the de-cerebrated body $\mathrm{A}$, whilst the other brain half of $\mathrm{B}$ is transplanted into the de-cerebrated body $\mathrm{C}$, then it will be the case that $\mathrm{B}$ will stand in a trans-temporal identity relation to both $\mathrm{A}$ and $\mathrm{C}$.

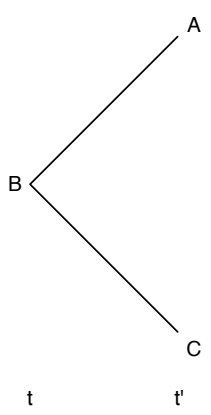


Fission cases are problematic since the transitivity of the identity relation seems to imply that if $A=B$ and $B=C$, then it follows that $A=C$, but at $t^{\prime}$ this is not the case since they are distinct. Gallois avoids this problem based on the transitivity of identity by employing a temporally qualified formulation of transitivity (cf. Gallois: I998, p. 70).

$$
\operatorname{Trans}_{\mathrm{t}}:(\mathrm{x})(\mathrm{y})(\mathrm{z})(\mathrm{t})[(\text { at } \mathrm{t}: \mathrm{x}=\mathrm{y} \& \text { at } \mathrm{t}: \mathrm{y}=\mathrm{z}) \rightarrow \text { at } \mathrm{t}: \mathrm{x}=\mathrm{z}]
$$

Since at $t: A=B$ and since at $t: B=C$ we only need at $t: A=C$ and this is indeed the case. The fact that at $\mathrm{t}^{\prime}: \neg(\mathrm{A}=\mathrm{C})$ is irrelevant and does not undermine transitivity, given that the transitivity of identity only holds at a particular time and not through time.

Case 2: We can establish the non-transitivity of the occasional identity relation by appealing to cases in which fissions and fusions occur simultaneously, such as tele-transporter accidents. ${ }^{2}$ These cases are such that at one instant we have $\mathrm{B}$ and $\mathrm{D}$ and at the next instant we have $\mathrm{A}, \mathrm{C}$ and $\mathrm{E}$. In such a case the following temporary identities hold: $A$ and $C$ are identical at t. Similarly, $C$ and $E$ are identical at t. Thus, $\mathrm{C}$ is both identical to $\mathrm{A}$ at $\mathrm{t}$ and identical to $\mathrm{E}$ at $\mathrm{t}$, but $\mathrm{A}$ and $\mathrm{E}$ are not identical at $t$, thereby undermining the transitivity of identity.

$A$ and $\mathrm{E}$ are only identical at $\mathrm{t}$ to things that are identical to each other at $\mathrm{t}^{\prime}$, but in order for transitivity to hold it must be the case that $\mathrm{A}$ and $\mathrm{E}$ themselves are identical at $t$. It is only true that at $t$ : at $t^{\prime}: A=E$, but this is not equivalent to at $t$ : $\mathrm{A}=\mathrm{E}$ since the temporal qualifiers are not redundant.

For example, consider again a situation in which preservation of one brain half is sufficient for trans-temporal identity and in which tele-transportation preserves identity. Both $\mathrm{B}$ and $\mathrm{D}$ enter into a tele-transporter that transports brain halves. The tele-transporter is then activated but malfunctions. Rather than tele-transporting both brain halves of $\mathrm{B}$ into one body and both of $\mathrm{D}$ into another body, one brain half of $\mathrm{B}$ ends up in body $\mathrm{A}$, one brain half of $\mathrm{D}$ ends up in body $\mathrm{E}$ and one brain half of each of B and D ends up in body C. In such a situation both B and D simultaneously undergo fission and fusion.

Thus we can see that the occasional identity thesis faces a problem insofar as when fissions and fusions occur simultaneously, we get two temporary identities without having transitivity of identity. We get a situation where at $t: A=C$ and at $t$ : $\mathrm{C}=\mathrm{E}$, but at $\mathrm{t}: \neg(\mathrm{A}=\mathrm{E})$.

\footnotetext{
${ }^{2}$ The reason why the fissions and fusions have to be simultaneous is explained in Appendix A.
} 
This can be represented diagrammatically:

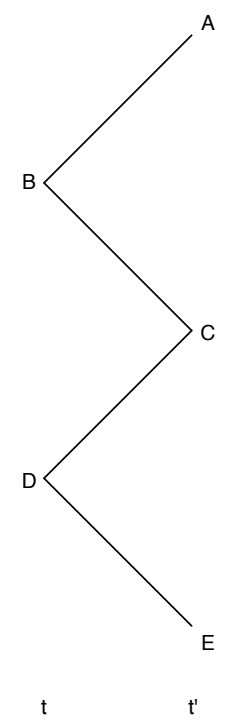

Applying the time-indexed version of the transitivity relation to the case at hand, we get:

$$
\text { (at t: } A=C \& \text { at } t: C=E) \rightarrow \text { at } t: A=E
$$

Since it is not the case that $\mathrm{A}=\mathrm{E}$ at $\mathrm{t}$, we can see that transitivity does not hold. Hence, the occasional identity relation does not even satisfy the temporally qualified transitivity relation. Since Gallois accepts that "[i]f it is anything, the relation of identity is a transitive relation" (Gallois: 1998, p. 75), it follows that the occasional identity relation is not an identity relation.

We might then think that occasional identity is something other than identity, however Gallois is very clear that it would be a mistake "to think that the occasional identity theorist has in mind a relation other than identity which she is misleadingly calling identity. ... The occasional identity view is a view about the two-place relation of identity that we all know and are perplexed by" (Gallois: I998, p. 7I).

In cases of simultaneous fissions and fusions, it turns out that at $\mathrm{t}: \mathrm{A}=\mathrm{C}$ and at $\mathrm{t}: \mathrm{C}=\mathrm{E}$, but at $\mathrm{t}: \neg(\mathrm{A}=\mathrm{E})$, which implies that the occasional identity relation is non-transitive. Accordingly, we have a refutation of OIT since we have uncovered an inconsistent triad:

(i) the occasional identity relation is the identity relation

(ii) the identity relation is transitive

(iii) the occasional identity relation is non-transitive 


\section{Contingent identity}

According to the Contingent Identity Thesis (CIT), two things can be identical at one world but distinct at another world.

$$
(\mathrm{CIT}) \diamond(\exists \mathrm{x})(\exists \mathrm{y})[\mathrm{x}=\mathrm{y} \& \diamond \neg(\mathrm{x}=\mathrm{y})]
$$

The contingent identity thesis is usually appealed to in order to solve problems concerning permanently coinciding entities (cf. Gibbard: 1975). Defenders of CIT want to say that objects that permanently coincide are identical since they share exactly the same spatio-temporal trajectory and are composed of the same parts (at some level of decomposition) at all times at which they exist. Yet, at the same time, they want to say that permanently coinciding objects could have been distinct, that they have different modal profiles and could have failed to coincide. CIT is much more widely defended and accepted than OIT. However, contingent identity faces the same problems as occasional identity.

In order to establish the non-transitivity of the contingent identity relation, we have to appeal to the modal analogues of fissions and fusions and construct a case in which multiple modal fissions and fusions are combined. Modal fissions and fusions occur if there is one thing in a world that is connected to two things in another world by means of trans-world identity relations.

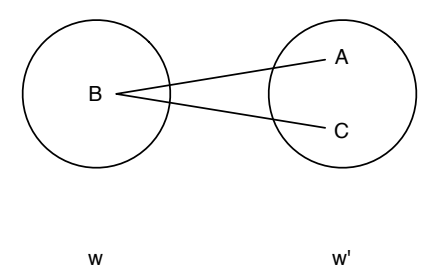

As in the case of occasional identity, this ordinary case of modal fission raises problems about the transitivity of the contingent identity relation insofar as the identities $A=B$ and $B=C$ imply, as a result of the transitivity of the identity relation, that $A=C$ but this is problematic since at $w^{\prime}: \neg(A=C)$.

These problems can be overcome by appealing to a world-indexed version of the transitivity requirement. According to the world-indexed version, the transitivity of the contingent identity relation only needs to hold within each world and not across worlds. ${ }^{3}$

$$
\operatorname{Trans}_{\mathrm{w}}:(\mathrm{x})(\mathrm{y})(\mathrm{z})(\mathrm{w})[(\text { at w: } \mathrm{x}=\mathrm{y} \& \text { at w: } \mathrm{y}=\mathrm{z}) \rightarrow \text { at } \mathrm{w}: \mathrm{x}=\mathrm{z}]
$$

\footnotetext{
${ }^{3}$ Some defenders of contingent identity are happy to concede that the contingent identity relation does not satisfy an inter-world transitivity requirement (cf. Nozick: 200I, p. I35). However, the subsequent argument will show that it does not even satisfy an intra-world transitivity requirement, which appears to be a highly problematic consequence of the contingent identity thesis.
} 
While this appeal to the revised form of the transitivity relation can deal with ordinary cases of modal fission and fusion, it fails to deal with cases in which we combine multiple fissions and fusions. These cases establish that the contingent identity thesis does not even satisfy the world-indexed version of the transitivity requirement. Appealing to the same strategy as in the discussion of OIT, we simply replace times by worlds so that we get a scenario in which at $\mathrm{w}$ : $\mathrm{A}=\mathrm{C}$ and at $\mathrm{w}: \mathrm{C}=\mathrm{E}$, but at $\mathrm{w}$ : $\neg(\mathrm{A}=\mathrm{E})$. In this way we can show that there is a failure of transitivity not just across worlds but even within a world.

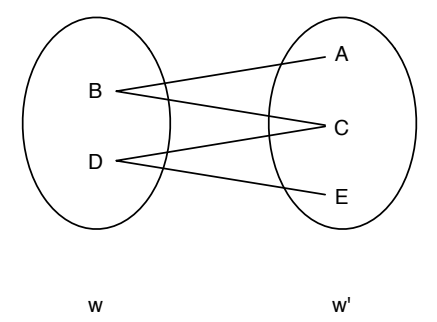

Instead of at w: $\mathrm{A}=\mathrm{E}$, which would be required by the Trans ${ }_{\mathrm{w}}$-relation, we only have the contingent identity at w: at w': $\mathrm{A}=\mathrm{E}$. This is because $\mathrm{A}$ and $\mathrm{E}$ are identical at $\mathrm{w}$ to things, namely $\mathrm{B}$ and $\mathrm{D}$, that are identical to each other at $\mathrm{w}$. Since the world-indices are not redundant, this does not reduce to at $\mathrm{w}$ : $\mathrm{A}=\mathrm{E}$ and we can thus see that the contingent identity relation is a non-transitive relation. We hereby have achieved a refutation of CIT since we have uncovered an inconsistent triad:

(i) the contingent identity relation is the identity relation

(ii) the identity relation is transitive

(iii) the contingent identity relation is non-transitive

\section{Sortal-relative identity and Abelardian predicates}

One way to save contingent identity from the transitivity objection is to make it sortal-relative. Gibbard defends the coherence of contingent identity by claiming that "it makes no sense to call a designator rigid and leave it at that, because it makes no strict sense to call things in different worlds identical and leave it at that: identity across possible worlds makes sense only with respect to a sortal" (Gibbard: 1975, p. I98).

When examining identities across worlds, we cannot simply ask whether B in $\mathrm{w}$ and $\mathrm{A}$ in $\mathrm{w}$ ' are the same thing. Instead, we need to ask whether $\mathrm{B}$ is the same $\mathrm{F}$ as A, for example whether it is the same statue or the same lump. Since different sortals can pick out different trans-world extensions, the possibility of contingent identity opens up. For instance, B in w can be the same lump as A in w' but the same statue as $\mathrm{C}$ in w', thereby making it the case that $\mathrm{A}$ and $\mathrm{C}$ are contingently identical at w. 
A related strategy has been suggested by Noonan who argues that modal predicates should be understood as Abelardian predicates, which means that the "reference of a modal predicate is dependent on the linguistic context in which it occurs, and in particular is dependent on the meaning of the singular term or phrase of restricted quantification to which it is attached" (Noonan: I99I, p. I88).

Accordingly, the reference of the modal predicate is contingently identical with' varies depending on the subject to which it is predicated. The statue $\mathrm{C}$ can then have the property of being contingently identical with $\mathrm{A}$ at $\mathrm{w}$, whilst the lump $\mathrm{C}$ can have the property of being contingently identical with $\mathrm{E}$ at $\mathrm{w}$. In this way one can defend contingent identity while holding onto rigid designation. One can allow for variations in the referents of modal predicates insofar as two rigid designators of the same object can differ in descriptive sense.

Given such a framework, we cannot simply say that A and C, as well as C and E, are identical at $\mathrm{w}$, and then claim that $\mathrm{A}$ and $\mathrm{E}$ also have to be identical if transitivity is to hold. Instead, we have to specify the sortals that fix the respective identities across possible worlds. For instance, it might be the case that at $\mathrm{w}$ A qua lump is identical to $\mathrm{C}$ qua statue and $\mathrm{C}$ qua lump is identical to $\mathrm{E}$ qua statue. With this in place, it is possible to block the argument that the contingent identity relation fails to be transitive. This is because even though $\mathrm{C}$ is contingently identical to both $\mathrm{A}$ and $\mathrm{E}$ at $\mathrm{w}$, the relation of being contingently identical to $\mathrm{A}$ is a relation that holds of $\mathrm{C}$ qua statue whilst the relation of being contingently identical to $\mathrm{E}$ is a relation that holds of $\mathrm{C}$ qua lump. Accordingly, since sortal-relative contingent identity must only obey a sortal-relative transitivity condition, it follows that there is no violation of transitivity given that a different sortal is involved.

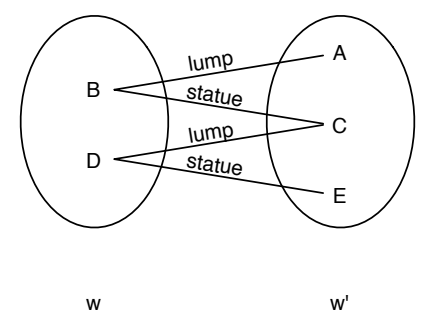

In order to establish the non-transitivity of the sortal-relative contingent identity relation, one would have to identify a case where the trans-world identities $\mathrm{C}=\mathrm{B}$ and $\mathrm{C}=\mathrm{D}$ fall under the same sortal, but this is neither possible on Gibbard's nor on Noonan's account. Thus, contingent identity does satisfy a sortal-qualified, world-indexed version of the transitivity requirement and is accordingly a transitive relation.

$$
\begin{aligned}
& \text { Trans }_{\mathrm{w}, \mathrm{qua}}:(\mathrm{x})(\mathrm{y})(\mathrm{z})(\mathrm{w})\left[\left(\text { at } \mathrm{w}: \mathrm{x}_{\text {quaF }}=\mathrm{y}_{\text {quaG }} \& \text { at } \mathrm{w}: \mathrm{y}_{\text {quaG }}=\mathrm{z}_{\text {quaH }}\right) \rightarrow\right. \text { at } \\
& \text { w: } \left.\mathrm{x}_{\text {quaF }}=\mathrm{z}_{\text {quaH }}\right]
\end{aligned}
$$


Whilst this strategy is successful in dealing with cases where different sortals are involved, it fails when we have contingent identities involving the same sortal. A defender of sortal-relative contingent identity can, of course, deny that there are such cases. However, this implies that we only have a restricted version of contingent identity that cannot explain many cases of apparent contingent identities. For example, we might want to say that two amoebas could have undergone fusion and are hence contingently identical in some world. The defender of sortal-relative identity would have to deny this possibility. ${ }^{4}$

Contingent identity is commonly appealed to in order to defend the thesis that constitution is identity. Since cross-sortal relations are usually at issue when it comes to the problem of material constitution, it seems that the 'constitution is identity' view can circumvent the transitivity worries as long as sortal-relative contingent identity is accepted. ${ }^{5}$

\section{Conclusion}

It has been established that both the occasional identity relation and the contingent identity relation are non-transitive relations, even failing to satisfy the time-indexed and the world-indexed transitivity requirements. Given that transitivity is essential to the identity relation, we can conclude that both of these relations do not classify as identity relations. The standard view of identity as a non-contingent and nontemporary relation has thus been defended against these alternative conceptions. ${ }^{6}$

${ }^{4} \mathrm{~A}$ similar account can be given for the temporal case, namely sortal-relative occasional identity (cf. Gupta: 1980, pp. 22-25, $45 \& 85$ ). Such an account consists of an acceptance of a sortalrelative trans-temporal identity relation combined with an affirmation of the possibility of occasional identities. The same considerations apply in that this strategy cannot solve transitivity worries when occasional identities result where the same sortal is at issue.

${ }^{5}$ It is important to note that sortal-relative contingent identity is a rather radical view. Since this view is committed to making the trans-world identity relation a sortal-relative relation, it can be considered as the modal analogue of Geach's relative identity thesis. Moreover, the predicationalshifts required by a defender of sortal-relative contingent identity lead to a number of problems that have been identified by Fine. These problems derive from the fact that defenders of Abelardian predicates have to argue that many linguistic contexts are opaque even though they appear to be transparent and that ordinary devices for making contexts transparent fail (cf. Fine: 2003; also cf. Koslicki: 2008, chapter 3). Furthermore, as Gray points out, while Gibbard and Noonan might well have provided us with a functioning semantics for contingent identity, they have not given us a plausible account of the metaphysics of contingent identity (cf. Gray: 200I, pp. 30-4I).

${ }^{6}$ For a discussion of cases involving simultaneous fissions and fusions in the context of counterpart-theoretic accounts of persistence and modality cf. Bader, R. M. 'Contingent identity, counterpart theory and the failure of transitivity' (manuscript). 


\section{Appendix}

\section{A The non-symmetry of the identity-at-t relation}

It might be asked why the fissions and fusions must occur simultaneously. In order to see why this has to be so, it is best to consider a case analogous to Case I, but where the fissions and fusions are not simultaneous, and then explain why such a case fails.

Case AI: At t, B and D both undergo fission, B splitting into A and $\mathrm{x}$, while $\mathrm{D}$ fissions to form $\mathrm{y}$ and $\mathrm{E}$. At $\mathrm{t}$ ', we have a fusion of $\mathrm{x}$ and $\mathrm{y}$ that forms $\mathrm{C}$. Exactly like in Case I it seems that we now have the following temporary identities. A and $\mathrm{C}$, as well as $\mathrm{C}$ and $\mathrm{E}$, are identical at $\mathrm{t}$, but $\mathrm{A}$ and $\mathrm{E}$ are not identical at $\mathrm{t}$, thereby undermining the transitivity of identity. $A$ and $E$ are only identical at $t$ to things that are identical to each other at $t^{\prime}$. It is only true that at $t$ : at $\mathrm{t}^{\prime}: \mathrm{A}=\mathrm{E}$, but this is not equivalent to at $\mathrm{t}: \mathrm{A}=\mathrm{E}$ since the temporal qualifiers are not redundant. Thus, it seems that Case $\mathrm{A}$ I constitutes a situation where at $\mathrm{t}$ : $\mathrm{C}=\mathrm{A}$ and at $\mathrm{t}: \mathrm{C}=\mathrm{E}$, but $\mathrm{A}$ is not identical to $\mathrm{E}$ at $\mathrm{t}$.

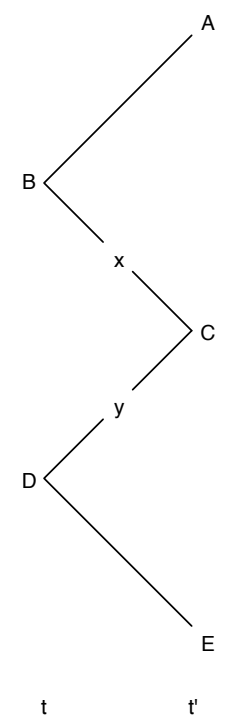

Applying the time-indexed version of the transitivity relation to the case at hand, we get:

(at $\mathrm{t}: \mathrm{A}=\mathrm{C} \&$ at $\mathrm{t}: \mathrm{C}=\mathrm{E}) \rightarrow$ at $\mathrm{t}: \mathrm{A}=\mathrm{E}$

However, since it is not the case that $\mathrm{A}=\mathrm{E}$ at $\mathrm{t}$, we can see that transitivity does not hold. Hence, the occasional identity relation does not even satisfy the temporally qualified transitivity relation.

Even though Case AI appears to be identical in the relevant respects to Case I, we have to note that it fails because at $\mathrm{t}: \neg(\mathrm{A}=\mathrm{C})$ and at $\mathrm{t}: \neg(\mathrm{C}=\mathrm{E})$. This is because 
the identity-at-t relation only holds between $\mathrm{x}$ and $\mathrm{y}$ "if there are a pair of times $\mathrm{t}$ and $\mathrm{t}$ ' such that everything identical with $\mathrm{x}$ at $\mathrm{t}$ is identical with $\mathrm{y}$ at $\mathrm{t}$.". (Gallois: I998, p. II6)

$$
(\mathrm{I} @ \mathrm{~T}) \square(\mathrm{x})(\mathrm{y})\left[\mathrm{x}=@_{\mathrm{t}} \mathrm{y} \leftrightarrow(\exists \mathrm{t})\left(\exists \mathrm{t}^{\prime}\right)(\mathrm{z})(\text { at } \mathrm{t}: \mathrm{z}=\mathrm{x} \rightarrow \text { at t’: } \mathrm{z}=\mathrm{y})\right]
$$

Now, $\mathrm{B}$ and $\mathrm{C}$ are not linked by the identity-at-t relation because there is a $\mathrm{z}$, namely $y$, to which $C$ is identical at $t$ ', while $B$ is not identical to this $z$ at $t$. Since at $t$ : $\neg(B=C)$ and since at $t: A=B$, it follows that at $t: \neg(A=C)$. The same holds for the at $\mathrm{t}: \mathrm{C}=\mathrm{E}$ relation that is required for Case $\mathrm{Ar}$ to succeed. In this case, there is a $\mathrm{z}$, namely $\mathrm{x}$, to which $\mathrm{C}$ is identical at $\mathrm{t}^{\prime}$, while $\mathrm{D}$ is not identical to this $\mathrm{z}$ at $\mathrm{t}$. Since at $\mathrm{t}: \neg(\mathrm{D}=\mathrm{C})$ and since at $\mathrm{t}: \mathrm{D}=\mathrm{E}$, it follows once again that at $\mathrm{t}: \neg(\mathrm{C}=\mathrm{E})$.

Since $A$ and $C$, as well as $C$ and $E$, are connected by a chain of identity-at- $t$ statements, it might seem that we can get the required at $t: A=C$ and at $t: C=E$. When looking at Case $\mathrm{A}_{\mathrm{I}}$, we see that $\mathrm{A}=\varrho_{\mathrm{t}} \mathrm{B}, \mathrm{B}=\varrho_{\mathrm{t}} \mathrm{x}, \mathrm{x}=\varrho_{\mathrm{t}} \mathrm{C}, \mathrm{C}=\varrho_{\mathrm{t}} \mathrm{y}, \mathrm{y}=\varrho_{\mathrm{t}} \mathrm{D}$, and $\mathrm{D}=@_{\mathrm{t}} \mathrm{E}$. However, we cannot get at $\mathrm{t}: \mathrm{A}=\mathrm{C}$ and at $\mathrm{t}: \mathrm{C}=\mathrm{E}$ given that the identity-at- $\mathrm{t}$ relation put forward by Gallois is non-symmetrical (cf. Gallois: I998, p. i I6). Accordingly, in Case $A \mathrm{I}$ we have $\mathrm{B}=@_{\mathrm{t}} \mathrm{x}$ and $\mathrm{x}=\mathrm{@}_{\mathrm{t}} \mathrm{C}$, but $\neg\left(\mathrm{B}=@_{\mathrm{t}} \mathrm{C}\right)$, without a violation of transitivity. Since $\mathrm{x}=\mathrm{B}$ at $\mathrm{t}$ and since $\mathrm{x}=\mathrm{C}$ at $\mathrm{t}^{\prime}$ and since the identity-at-t relation is not symmetrical, we do not get at $\mathrm{t}$ : $\mathrm{C}=\mathrm{B}$.

When representing the 'direction' of temporal identity by means of vector arrows, we can see that there is no intransitivity since we only get the following identity-at-t statements:

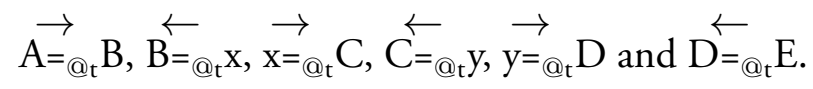

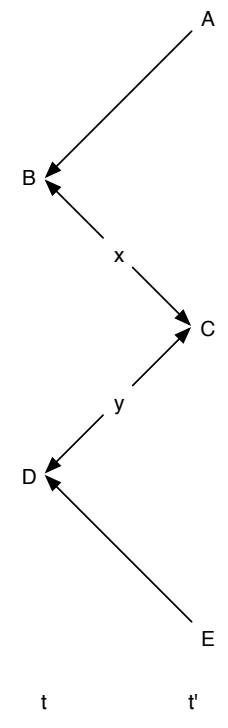




\section{A.I Simultaneous fission and fusion}

Case A2: We can salvage the idea underlying Case AI by slightly modifying the example. In Case $\mathrm{AI}$, we can rule out $\mathrm{C}=@_{\mathrm{t}} \mathrm{D}$ by means of the $\mathrm{C}=\mathrm{@}_{\mathrm{t}} \mathrm{x}$ relation. At $\mathrm{t}^{\prime}: \mathrm{C}=\mathrm{x}$ and at $\mathrm{t}: \neg(\mathrm{D}=\mathrm{x})$. Accordingly, $\mathrm{C}=\mathrm{@}_{\mathrm{t}} \mathrm{D}$ does not satisfy $\mathrm{I} @ \mathrm{~T}$ and is hence ruled out. The same applies to $C=@_{\mathrm{t}} \mathrm{B}$ since at t': $\mathrm{C}=\mathrm{y}$ but at $\mathrm{t}: \neg(\mathrm{B}=\mathrm{y})$. However, this problem can be fixed by appealing to cases where fissions and fusions occur simultaneously. These cases are such that at one instant we have B and D and at the next instant we have $\mathrm{A}, \mathrm{C}$ and $\mathrm{E}$. There are no intermediary objects, such as $\mathrm{x}$ and $y$, that are identical to $C$ at $t^{\prime}$ that could be used to rule out $C=@_{t} B$ and $C=@_{t} D$. Accordingly, we get the following identity-at-t relations:

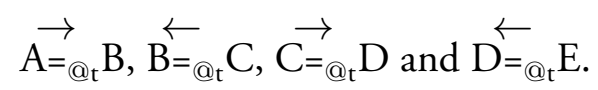

From this it follows that at $\mathrm{t}: \mathrm{A}=\mathrm{C}$ and at $\mathrm{t}: \mathrm{C}=\mathrm{E}$, but at $\mathrm{t}: \neg(\mathrm{A}=\mathrm{E})$.

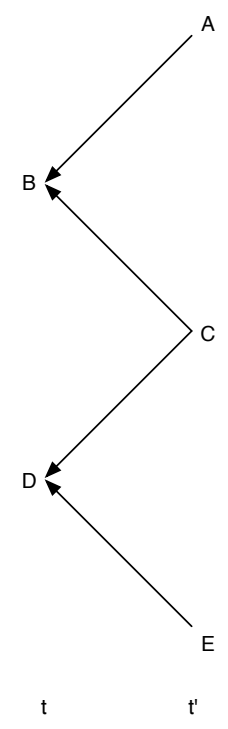

In a normal case of fusion, we can use the identity-at-t relation going in one direction from $B$ to $C$, i.e. $\overrightarrow{B=} @_{t} C$, in order to establish the identity $B=C$ at $t$ '. This occasional identity can then be used to rule out the identity-at-t relation from $\mathrm{C}$ to

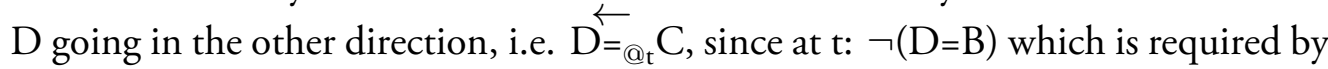
I@T. However, in Case $\mathrm{A} 2$ we have no identity-at-t relation going to $\mathrm{C}$ that could be used to rule out identity-at-t relations going away from $\mathrm{C}$. This is because the fission cases ensure that no such relations obtain, since the occasional identity at $t: A=B$ rules out $\overrightarrow{B=}{ }_{@ \mathrm{t}} \mathrm{C}$ since this identity-at-t relation would require $\mathrm{C}$ to be identical to $A$ at $\mathrm{t}^{\prime}$. The same holds for the relation between $\mathrm{D}$ and $\mathrm{C}$, insofar as the occasional identity at $t: E=D$ rules out $\overrightarrow{\mathrm{D}=@_{\mathrm{t}}} \mathrm{C}$ since this identity-at-t relation would require 
$\mathrm{C}$ to be identical to $\mathrm{E}$ at $\mathrm{t}^{\prime}{ }^{7}$ This is what is special about simultaneous fissions and fusions, namely that both the branches connecting $\mathrm{C}$ to $\mathrm{B}$ and $\mathrm{C}$ to $\mathrm{D}$ are such that there are no identity-at-t relations 'going to' $\mathrm{C}$ that could be used for ruling out identity-at-t relations 'going away' from $\mathrm{C}$. The identity-sustaining relation between $\mathrm{C}$ and $\mathrm{B}$ is sufficient for the identity-at-t relation $\mathrm{B}={ }_{@_{\mathrm{t}}} \mathrm{C}$ to hold in the absence of there being something at $\mathrm{t}^{\prime}$ to which $\mathrm{C}$ is identical and to which $\mathrm{B}$ is not identical at $\mathrm{t}$. At $\mathrm{t}^{\prime} \mathrm{C}$ is only identical to $\mathrm{C}$ and hence any object standing in an identitysustaining relation to $\mathrm{C}$ will be related to $\mathrm{C}$ by I@T. Since both B and D stand in identity-sustaining relations to $\mathrm{C}$, they are both identical-at-t to $\mathrm{C}$, i.e. ${\mathrm{B}={ }_{\mathrm{Q}} \mathrm{C}}_{\mathrm{C}}$ and $\mathrm{D}_{{ }_{@ \mathrm{t}}}^{\leftarrow} \mathrm{C}^{8}$

Thus, we can conclude that Case AI fails due to the non-symmetry of the identity-at-t relation. However, we can save the argument by appealing to cases involving simultaneous fissions and fusions. In Case $A 2$ it is the case that at $t: A=C$ and at $\mathrm{t}: \mathrm{C}=\mathrm{E}$, but at $\mathrm{t}: \neg(\mathrm{A}=\mathrm{E})$ which implies that the occasional identity relation is non-transitive. ${ }^{9}$

\footnotetext{
${ }^{7}$ As an anonymous referee has pointed out, the identities at $\mathrm{t}: \mathrm{A}=\mathrm{C}$ as well as at $\mathrm{t}: \mathrm{C}=\mathrm{E}$ would be lost, if it should be possible for Gallois to find a way of establishing at $t^{\prime}: C=B$ as well as at $t^{\prime}: C=D$. This, however, cannot be done by appealing to the I@T principle and Gallois does not recognise any other principle for establishing temporary identities.

${ }^{8}$ It might be suggested that $\mathrm{C}$ is not I@T-related to anything, that the fusion of two fissions somehow creates an entirely new object. However, this would be unjustified in the sense that there would be nothing that is identical to $\mathrm{C}$ at $\mathrm{t}$ ' that could be used for ruling out candidates for identityat- $t$ that are related to $\mathrm{C}$ by means of identity-sustaining relations. Moreover, if $\mathrm{C}$ would not be related by identity-at-t relations to $\mathrm{B}$ and $\mathrm{D}$ in either direction, then we would get a scenario in which $\overleftrightarrow{\mathrm{B}=} @_{\mathrm{t}} \mathrm{A}$ and $\overleftrightarrow{\mathrm{D}=}_{@_{\mathrm{t}}} \mathrm{E}$. This symmetric identity-at-t relation between $\mathrm{A}$ and $\mathrm{B}$, as well as between $\mathrm{D}$ and $\mathrm{E}$, would undermine the claim of "identity-sustaining relations failing to ensure identity in branching cases" (Gallois: I998, p. 94). We would get these symmetric relations because even though B would split into A and C, C would not be identical to B at $t$ and, consequently, everything that would be identical to $B$ at $t$ would be identical to $A$ at $t$ '.

${ }^{9}$ For helpful comments I would like to thank Daniel Nolan, André Gallois, Katherine Hawley and Ira Kiourti, as well as audiences at St Andrews and Boulder.
} 


\section{References}

[I] Fine, K. The Non-Identity of a Material Thing and Its Matter. Mind II2, 446 (2003), I95-234.

[2] Gallois, A. Occasions of Identity: The Metaphysics of Persistence, Change, and Sameness. Clarendon Press, Oxford, I 998.

[3] Gibbard, A. Contingent Identity. Journal of Philosophical Logic 4 (1975), I $87-22$ I .

[4] Gray, A. The Semantics and Metaphysics of Contingent Identity. PhD thesis, Massachusetts Institute of Technology, 200I.

[5] Gupta, A. The Logic of Common Nouns - An Investigation in Quantified Modal Logic. Yale University Press, I980.

[6] Kosuicki, K. The Structure of Objects. Oxford University Press, 2008.

[7] Noonan, H. W. Indeterminate Identity, Contingent Identity and Abelardian Predicates. The Philosophical Quarterly 4I, I63 (I99I), I83-193.

[8] Nozick, R. Invariances: The structure of the objective world. Harvard University Press, 200I. 